\title{
Three-component reactions of aromatic amines, 1,3-dicarbonyl compounds, and $\alpha$-bromoacetaldehyde acetal to access $N$-(hetero)aryl-4,5-unsubstituted pyrroles
}

\author{
Wenbo Huang ${ }^{1}$, Kaimei Wang ${ }^{1}$, Ping $\mathrm{Liu}^{2}$, Minghao $\mathrm{Li}^{3}$, Shaoyong Ke ${ }^{* 1}$ \\ and Yanlong $\mathrm{Gu}^{* 2,3}$
}

\section{Letter}

\section{Address:}

${ }^{1}$ National Biopesticide Engineering Research Centre, Hubei Biopesticide Engineering Research Centre, Hubei Academy of Agricultural Sciences, 8 Nanhu Avenue, Hongshan District, Wuhan 430064, China, ${ }^{2}$ School of Chemistry and Chemical Engineering, The Key Laboratory for Green Processing of Chemical Engineering of Xinjiang Bingtuan, Shihezi University, Shihezi City 832004, China and ${ }^{3}$ Key laboratory of Material Chemistry for Energy Conversion and Storage, Ministry of Education, Hubei Key Laboratory of Material Chemistry and Service Failure, School of Chemistry and Chemical Engineering, Huazhong University of Science and Technology, 1037 Luoyu road, Hongshan District, Wuhan 430074, China

Email:

Shaoyong Ke* - shaoyong.ke@nberc.com; Yanlong Gu* -

klgyl@hust.edu.cn

* Corresponding author

Keywords:

acid catalyst; [1 + 2 + 2] annulation; KI; pyrazolo[3,4-b]pyridine; pyrroles

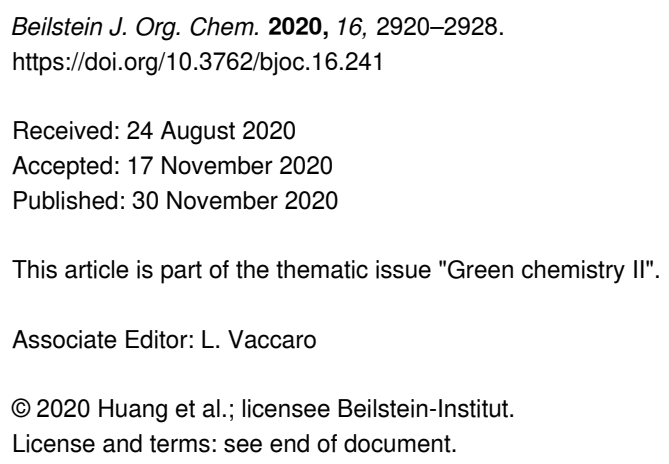

\begin{abstract}
$N$-(Hetero)aryl-4,5-unsubstituted pyrroles were synthesized from (hetero)arylamines, 1,3-dicarbonyl compounds, and $\alpha$-bromoacetaldehyde acetal by using aluminum(III) chloride as a Lewis acid catalyst through $[1+2+2]$ annulation. This new versatile methodology provides a wide scope for the synthesis of different functional $N$-(hetero)aryl-4,5-unsubstituted pyrrole scaffolds, which can be further derived to access multisubstituted pyrrole-3-carboxamides. In the presence of 1.2 equiv of KI, a polysubstituted pyrazolo $[3,4-b]$ pyridine derivative was also successfully synthesized.
\end{abstract}

\section{Introduction}

Among nitrogen-containing heterocycles, pyrroles have garnered significant attention in the literature because of their presence in various natural products [1-4] and pharmaceutically relevant drugs [5,6]. Accordingly, numerous synthetic methods to construct pyrrole skeletons were reported, including the classical Hantzsch $[7,8]$ and the Paal-Knorr pyrrole syntheses 
[9-11], which have been developed to harvest the pyrrole frameworks. In the past few years, the interest in developing new methods to synthesize this heterocyclic motif has rapidly grown; transition metal-catalyzed cyclization [12-14] and multicomponent reactions [15-18] are some of the commonly used approaches for the construction of pyrrole scaffolds. Additionally, the biocatalytic synthesis of substituted pyrroles was also developed [19]. Though sustained efforts have been achieved to develop efficient synthetic methods for the preparation of this structural motif [20-23], the development of cost-effective methods to access functionalized pyrrole skeletons has remained an ongoing challenge.

$N$-(Hetero)aryl-4,5-unsubstituted pyrroles are one of the most important types of pyrroles, which are frequently used as a core scaffold in pharmaceuticals (Figure 1) [24,25]. Therefore, many efforts have been paid to the synthesis of these privileged pyrroles. (Hetero)arylamines are readily available chemicals. The direct conversion of (hetero)arylamines into $N$-(hetero)aryl4,5-unsubstituted pyrroles has a high intrinsic synthetic potential. At present, the transformations can generally be realized through the following three approaches (Scheme 1): (i) $[1+1+3]$ annulation, in which (hetero)arylamines are reacted with a $\mathrm{C}_{3}$ donor and a $\mathrm{C}_{1}$ donor to construct pyrrole scaffolds. Kumar et al. [26] developed a proline-catalyzed Mannich reaction-cyclization sequence of succinaldehyde and an in situ-generated arylimine, in which the succinaldehyde contributes three carbon atoms to the pyrrole ring. $\alpha, \beta$-Unsaturated aldehydes have also been used as the $\mathrm{C}_{3}$ donor to construct pyrrole scaffolds [27,28]; (ii) $[1+4]$ annulation, in which (hetero)arylamines are reacted with a $\mathrm{C}_{4}$ donor to form the pyrrole ring; many functional molecules, such as bioderived furans [29], (Z)-enynols [30], 1-vinylpropargyl alcohols [31], doubly activated cyclopropanes [32], and enynals [33], can be used as $\mathrm{C}_{4}$ counter reagents. The carbon-based 1,4-biselectrophiles, such as the 1,4-dicarbonyl compounds [34,35], $\gamma$-car- bonyl tert-butyl peroxides [36], and dihydrofurans [37] have also been reported to construct the pyrrole skeletons through this type of annulation; and (iii) $[1+2+2]$ annulation, in which (hetero)arylamines are reacted with two different molecules, and each of them contributes two carbon atoms to construct a pyrrole ring [38-42]. Among these three approaches, the third is considered the most attractive route for $N$-(hetero)aryl-4,5-unsubstituted pyrrole synthesis. The reason is twofold: (i) the strategy uses easily available substrates and (ii) permits to synthesize pyrroles with a high potential of molecular diversity and complexity. However, to date, the productivity for creating molecular diversity and complexity has yet to be fully displayed. In addition, some of the reported approaches were established on the basis of using expensive and nonrecyclable homogeneous metal catalysts. To alleviate all these problems, herein, we used easily available $\alpha$-bromoacetaldehyde acetal (2a) and a simple 1,3-dicarbonyl compound as a reagent couple to react with (hetero)arylamines. The established $[1+2+2]$ annulation reaction provided a straightforward approach for accessing various $N$-(hetero)aryl-4,5-unsubstituted pyrroles, and some of the pyrrole products are not accessible with the methods reported hitherto.

\section{Results and Discussion}

Initially, a mixture of aniline (1a), $\alpha$-bromoacetaldehyde acetal (2a), and ethyl acetoacetate (3a) was treated under the conditions; the obtained results are listed in Table 1. The mixture was heated in 1,4-dioxane at $80{ }^{\circ} \mathrm{C}$. No reaction occurred in the absence of the catalyst (Table 1, entry 1); however, in the presence of the strong Lewis acid $\mathrm{Bi}(\mathrm{OTf})_{3}$, the expected product $4 \mathbf{a}$ was obtained in $36 \%$ yield after $6 \mathrm{~h}$ of reaction (Table 1, entry 2). To our surprise, the $N$-aryl-4,5-unsubstituted pyrrole derivative $4 \mathbf{a}$ was isolated in $80 \%$ yield when $10 \mathrm{~mol} \%$ of $\mathrm{AlCl}_{3}$ was used as the catalyst (Table 1 , entry 3 ). $\mathrm{FeCl}_{3}$ and $\mathrm{NiCl}_{2}$ were also proven to catalyze this reaction, but the yield of $\mathbf{4 a}$ was inferior to those obtained with $\mathrm{AlCl}_{3}$ (Table 1, entries 4 and 5).

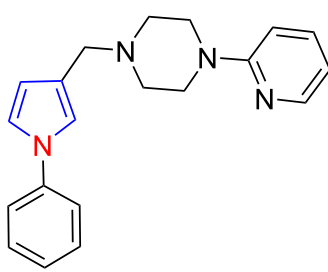

antipsychotic agent<smiles>Cc1cc(C(N)=O)ccc1-c1c(CCC(=O)O)ccn1-c1ccc(-n2ccnc2)cc1</smiles>

GSNOR inhibitor<smiles>Cc1ccc(-n2ccc(C(F)(F)F)c2COc2c(F)cc(CCC(=O)O)cc2F)cn1</smiles>

GPR120 agonist 
approaches to $\mathrm{N}$-(heteroaryl)-4,5-unsubstituted pyrroles from (heteroaryl)amines:

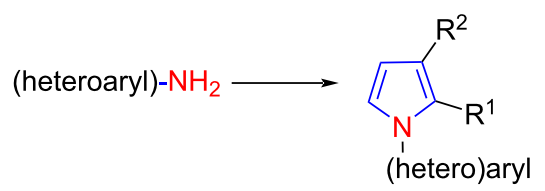

$[1+1+3]$ annulation:

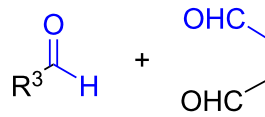

oxidant (1.2 equiv) Kumar et al. 2018 [26]<smiles>[R]C#C[PH2+]</smiles>

$-78^{\circ} \mathrm{C}$, multistep

Thompson; Montgomery 2011 [27]<smiles>O=CC=Cc1ccccc1</smiles>

Ru cat. Biletzki; Imhof 2011 [28]

$[1+4]$ annulation:<smiles>[R]c1ccoc1[R]</smiles>

$150{ }^{\circ} \mathrm{C}$<smiles>[R]C#CC([R7])=CCO</smiles>

Ag-Au cat.

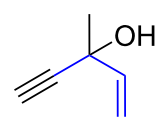

Ru cat., $100^{\circ} \mathrm{C}$ Haak et al. 2013 [31]<smiles>[R]C(=O)C1(C([R])=O)CC1</smiles>

Fe cat. ( 0.5 equiv), $100^{\circ} \mathrm{C}$ Zhang et al. 2014 [32]<smiles>C#CC(C=O)=C[Te]</smiles>

Ag cat.<smiles>CCCCOC(=O)C(CC=O)C(C)=O</smiles>

Lambeth et al. 2004 [34]<smiles>CCOC(=O)C(CC=O)C(=O)c1ccccc1</smiles>

Henichart et al. 2005 [35]<smiles>[R]C(=O)C(CC(OC(C)(C)C)c1ccccc1)C([R1])=O</smiles>

$\mathrm{TfOH}$ (1.0 equiv) Li et al. 2017 [36]<smiles>CCCCOC1CC(C(=O)OC)=C(C)O1</smiles>

$\mathrm{CH}_{3} \mathrm{NO}_{2}, 100^{\circ} \mathrm{C}$ Gu et al. 2016 [37]

$[1+2+2]$ annulation:<smiles>[R14]C[14CH2][14CH2][R3]([R])=O</smiles><smiles>[R6]OC(=O)C#CC=[R6]</smiles>

two steps, 1 example Zhang et al. 2018 [42]

Ru cat., ligand, $130^{\circ} \mathrm{C}$ Beller et al. $2013[38,39]$

this work:

Ru cat., $130{ }^{\circ} \mathrm{C}$

Chandrasekhar et al. 2014 [40]

Cu-NHC cat., $140{ }^{\circ} \mathrm{C}$

Dang; Seayad 2017 [41]

Scheme 1: Typical routes to $N$-(heteroaryl)-4,5-unsubstituted pyrroles.

p-Toluenesulfonic acid (PTSA), a strong Brønsted acid, also exhibited a promising catalytic ability, and the yield of $\mathbf{4 a}$ reached $73 \%$ (Table 1, entry 6). When HOAc was used, only unreacted starting materials were recovered (Table, entry 7). The effect of the solvent on the model reaction was also examined. Anhydrous ethanol, acetonitrile, toluene, and DMSO did not bring any improvement with respect to the yield of $\mathbf{4 a}$
(Table 1, entries 8-11). The decrease of the catalyst loading from 10 to $5 \mathrm{~mol} \%$ resulted in a slight decrease of the reaction yield (Table 1, entry 12). Further investigations revealed that the reaction was also affected by the temperature and time; a yield of only $51 \%$ was obtained at $50{ }^{\circ} \mathrm{C}$ (Table 1 , entries 13 and 14). Therefore, the optimized reaction conditions were confirmed as the following: $10 \mathrm{~mol} \%$ of $\mathrm{AlCl}_{3}$ as a catalyst, 1,4- 
Table 1: Optimization of the conditions for the reaction between $\mathbf{1 a}, \mathbf{2 a}$, and $\mathbf{3 a}$. $^{\mathrm{a}}$

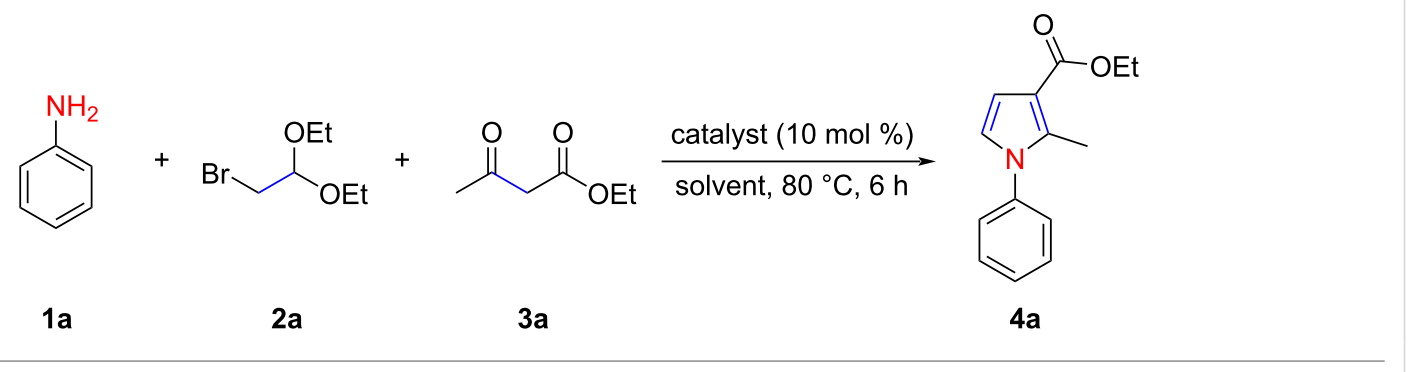

\begin{tabular}{|c|c|c|c|}
\hline entry & catalyst & solvent & yield $(\%)^{b}$ \\
\hline 1 & - & 1,4-dioxane & 0 \\
\hline 2 & $\mathrm{Bi}(\mathrm{OTf})_{3}$ & 1,4-dioxane & 36 \\
\hline 3 & $\mathrm{AlCl}_{3}$ & 1,4-dioxane & 80 \\
\hline 4 & $\mathrm{FeCl}_{3}$ & 1,4-dioxane & 44 \\
\hline 5 & $\mathrm{NiCl}_{2}$ & 1,4-dioxane & 21 \\
\hline 6 & PTSA & 1,4-dioxane & 73 \\
\hline 7 & HOAc & 1,4-dioxane & trace \\
\hline 8 & $\mathrm{AlCl}_{3}$ & $\mathrm{EtOH}$ & 31 \\
\hline 9 & $\mathrm{AlCl}_{3}$ & $\mathrm{MeCN}$ & 50 \\
\hline 10 & $\mathrm{AlCl}_{3}$ & PhMe & 27 \\
\hline 11 & $\mathrm{AICl}_{3}$ & DMSO & 62 \\
\hline $12^{c}$ & $\mathrm{AlCl}_{3}$ & 1,4-dioxane & 55 \\
\hline $13^{d}$ & $\mathrm{AlCl}_{3}$ & 1,4-dioxane & 51 \\
\hline $14^{e}$ & $\mathrm{AICl}_{3}$ & 1,4-dioxane & 40 \\
\hline $15^{f}$ & $\mathrm{AlCl}_{3}$ & 1,4-dioxane & 72 \\
\hline
\end{tabular}

a1a: $0.5 \mathrm{mmol}$, 2a: $0.6 \mathrm{mmol}$, 3a: $0.6 \mathrm{mmol}$, catalyst: $0.05 \mathrm{mmol}$, solvent: $1 \mathrm{~mL}, 80^{\circ} \mathrm{C}, 6 \mathrm{~h}$. ${ }^{\mathrm{b}}$ Isolated yield, calculated with respect to $1 \mathrm{a}$. ${ }^{\mathrm{c}} \mathrm{AlCl}_{3}: 0.025 \mathrm{mmol} .{ }^{\mathrm{d}} 50{ }^{\circ} \mathrm{C}$. ${ }^{\mathrm{e}} 2 \mathrm{~h} .{ }^{\mathrm{f}} 10 \mathrm{mmol}-\mathrm{scale}$ reaction.

dioxane as a solvent, $6 \mathrm{~h}$, and $80^{\circ} \mathrm{C}$. It is worth noting that the reaction can be effectively scaled up with similar efficiency. In a gram-scale synthesis of $\mathbf{4 a}$, the corresponding pyrrole product was obtained in $72 \%$ yield (Table 1, entry 15 ).

The scope of this synthetic protocol for pyrroles was then investigated under the optimized reaction conditions. The substrate scope of the 1,3-dicarbonyl component was first examined (Scheme 2). Acetylacetone reacted smoothly with 1a and 2a to form $4 \mathbf{b}$ in 52\% yield. 1,3-Dicarbonyl compounds bearing an ester group readily participated in this reaction, affording the desired pyrroles $\mathbf{4 c}-\mathbf{e}$ in moderate to good yield. Notably, methyl 2-methyl-1-phenyl-1 $H$-pyrrole-3-carboxylate $(\mathbf{4 c})$ is a key intermediate in the synthesis of a TRPM8 antagonist [43]. The substrate scope of the aromatic amine component was then examined, and the remarkable efficiency of our pyrrole synthesis was reflected by the tolerance of a broad range of functional groups attached to the aromatic amine. For example, anilines bearing methyl (in 4f), phenyl (in $\mathbf{4 g}$ ), and halo functionalities (in $\mathbf{4 h}-\mathbf{m}$ ) were readily compatible with the $\mathrm{AlCl}_{3}$ and 1,4dioxane system. In these cases, the pyrrole products were isolat- ed in moderate to good yield. The presence of an electrondonating group in the phenyl ring facilitated the progress of the reaction to some extent, resulting in $\mathbf{4 n}$. Anilines with electronwithdrawing groups, such as an acetyl or carboxy group, can also be used in the reaction, but the yields obtained for $\mathbf{4 0}$ and 4p were slightly inferior. Gratifyingly, a 3,5-dichloro-4(1,1,2,2-tetrafluoroethoxy)aniline also participated smoothly in this reaction, and the expected product $\mathbf{4 q}$ can be obtained in $75 \%$ yield. This fluorinated substituent on the aniline ring has been identified as the key precursor to access the insect-growth regulators [44]. It is noteworthy that the sulfonamide group persisted during this transformation, and the desired pyrrole product $4 \mathbf{r}$ could be obtained in $69 \%$ yield. A high yield was also obtained when the phenyl group was replaced with a naphthyl group in $\mathbf{4 s}$. Subsequently, aliphatic primary amines and ammonia, such as benzylamine and $N$-butylamine, were also examined as nitrogen donors; however, no desired product was detected.

Then, we attempted to synthesize pharmaceutically active $\mathrm{N}$-heterocyclic pyrrole derivatives with the aid of this three- 


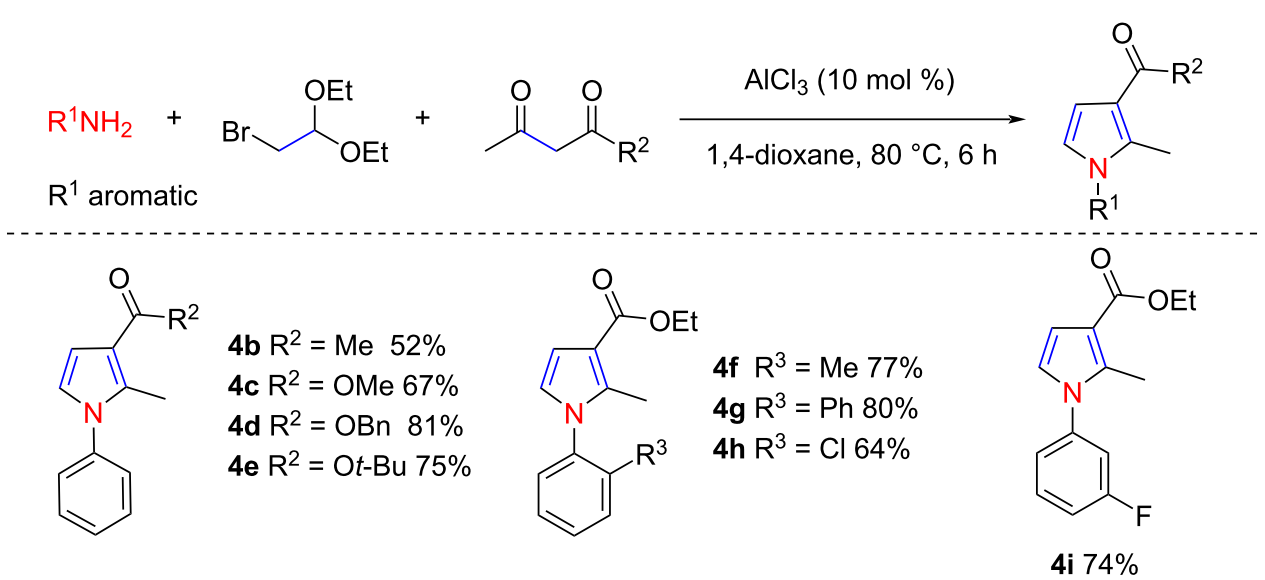<smiles>CCOC(=O)c1ccn(-c2ccc(F)cc2OC)c1C</smiles><smiles>[R]COC(=O)c1ccn(-c2ccc([R4])cc2)c1C</smiles>

4k $\mathrm{R}^{4}=\mathrm{F} \quad 65 \%$

4l $\mathrm{R}^{4}=\mathrm{Cl} 71 \%$

$4 \mathrm{~m} \mathrm{R} \mathrm{R}^{4}=\mathrm{Br} 73 \%$

4n $\mathrm{R}^{4}=$ OMe $86 \%$

4j $73 \%$<smiles>CCOC(=O)c1ccn(-c2cc(Cl)c(OC(F)(F)F)c(Cl)c2)c1C</smiles>

$4 q 75 \%$<smiles>CCOC(=O)c1ccn(-c2ccc(S(=O)(=O)Nc3ccccc3-c3ccccc3)cc2)c1C</smiles><smiles>CCOC(=O)c1ccn(-c2ccc(C(C)=O)cc2)c1C</smiles>

$4065 \%$<smiles>CCOC(=O)c1ccn(-c2ccc(C(=O)O)cc2C)c1C</smiles>

4p $53 \%$

Scheme 2: Substrate scope of the pyrrole synthesis.

component reaction. To our great delight, the N-heterocyclic pyrrole skeletons $4 \mathbf{t}-\mathbf{v}$ were successfully synthesized in $51-85 \%$ yield by using our protocol (Scheme 3 ). It should be mentioned that the obtained $N$-pyridylpyrroles $\mathbf{4 t}$ and $\mathbf{4} \mathbf{u}$ are a class of very important intermediates for synthesizing the soluble guanylyl cyclase (sGC) activator. A reported method for accessing these similar scaffolds suffers from a low product yield and harsh reaction conditions $\left(32 \%, 130{ }^{\circ} \mathrm{C}\right)[45,46]$.

One of the obtained $N$-aryl-4,5-unsubstituted pyrroles, 4l, could undergo hydrolysis to form the (pyrrol-3-yl)carboxylic acid $\mathbf{4 w}$. The latter can react readily with aniline (1a) or amantadine in the presence of HATU or EDCI to form the multisubstituted pyrrole-3-carboxamide derivatives $\mathbf{4 x}$ and $\mathbf{4 y}$ (Scheme 4). These skeletons have been proven to be promising inhibitors for the production of cytokines [47].<smiles>CCOC(=O)c1ccn(-c2ccc(Cl)nc2)c1C</smiles><smiles>CCOC(=O)c1ccn(-c2cc(Br)cnc2Cl)c1C</smiles><smiles>CCOC(=O)c1ccn(-c2noc(C)c2C)c1C</smiles>

4t $85 \%$ 4v $51 \%$

A plausible mechanism for the model reaction was proposed and is depicted in Scheme 5. Initially, a reaction of $\mathbf{1 a}$ and $\mathbf{3 a}$ occurred, providing an imine intermediate $\mathbf{I}$, which tautomerized to the corresponding enamine form. Meanwhile, the activa- 


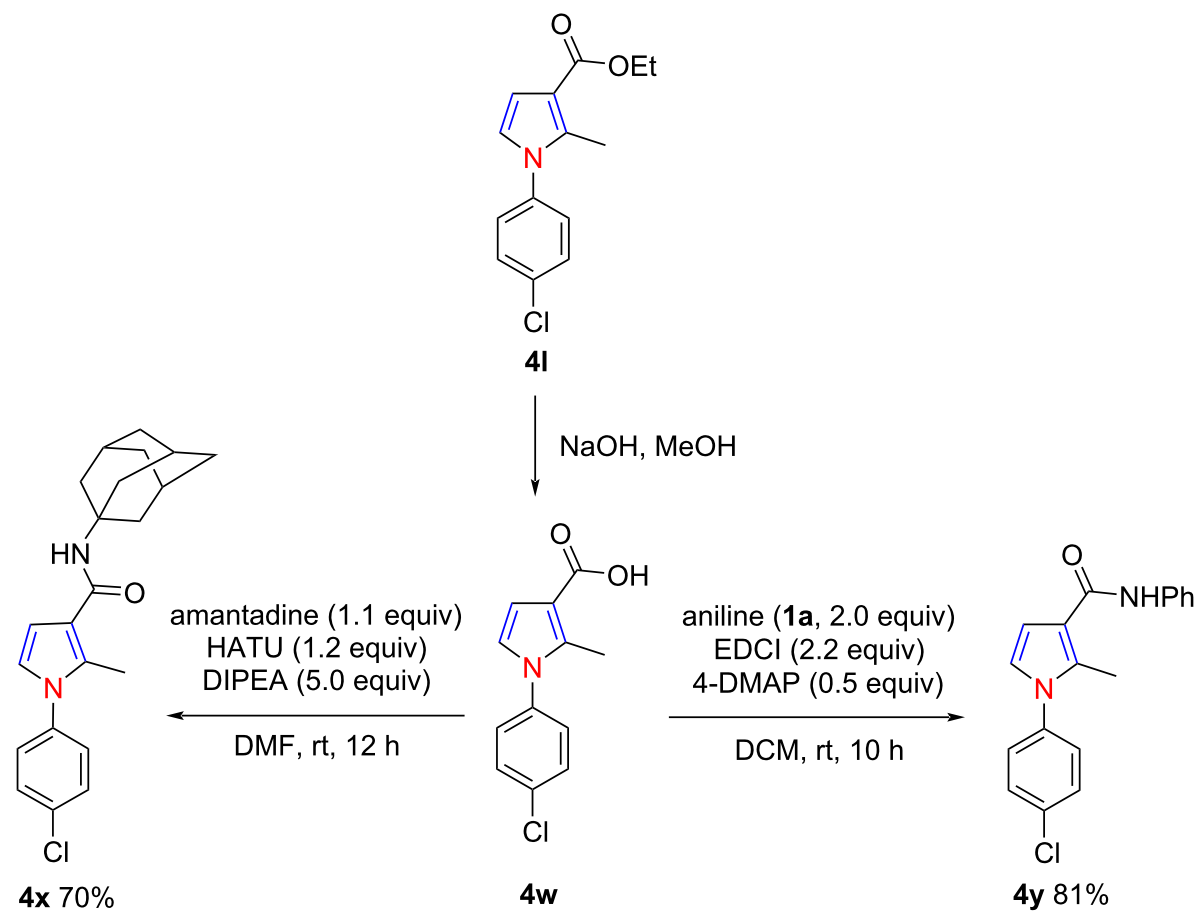

Scheme 4: Direct synthesis of pyrrole-3-carboxamide derivatives.

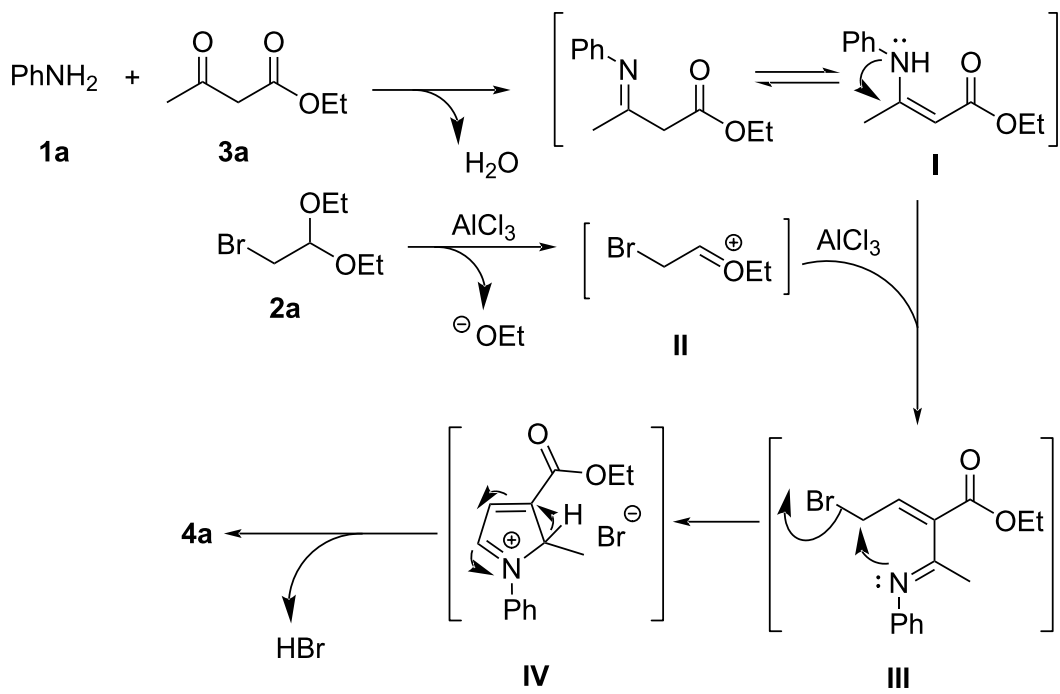

Scheme 5: Plausible mechanism of the three-component reaction.

tion of $2 \mathbf{a}$ with $\mathrm{AlCl}_{3}$ allowed the formation of a carbocation intermediate II, which was then trapped by the enamine intermediate I to generate another intermediate III. Subsequently, III underwent an intramolecular electrophilic substitution to form the intermediate IV. Finally, IV underwent an elimination of $\mathrm{HBr}$ and a spontaneous aromatization to afford the pyrrole product 4a $[48,49]$.
Apart from the pyrrole synthesis, we also observed an unexpected reaction in which the pyrazolo[3,4- $b]$ pyridine scaffold was constructed under analogous conditions. As shown in Scheme 6, In the presence of a catalytic amount of $\mathrm{AlCl}_{3}$ and 1.2 equiv of KI, 3-methyl-1-phenyl-1H-pyrazol-5-amine (1) reacted smoothly with $\mathbf{2 a}$ and $\mathbf{3 a}$, affording the polysubstituted pyrazolo[3,4-b]pyridine 5a in 53\% yield. The formation of an 


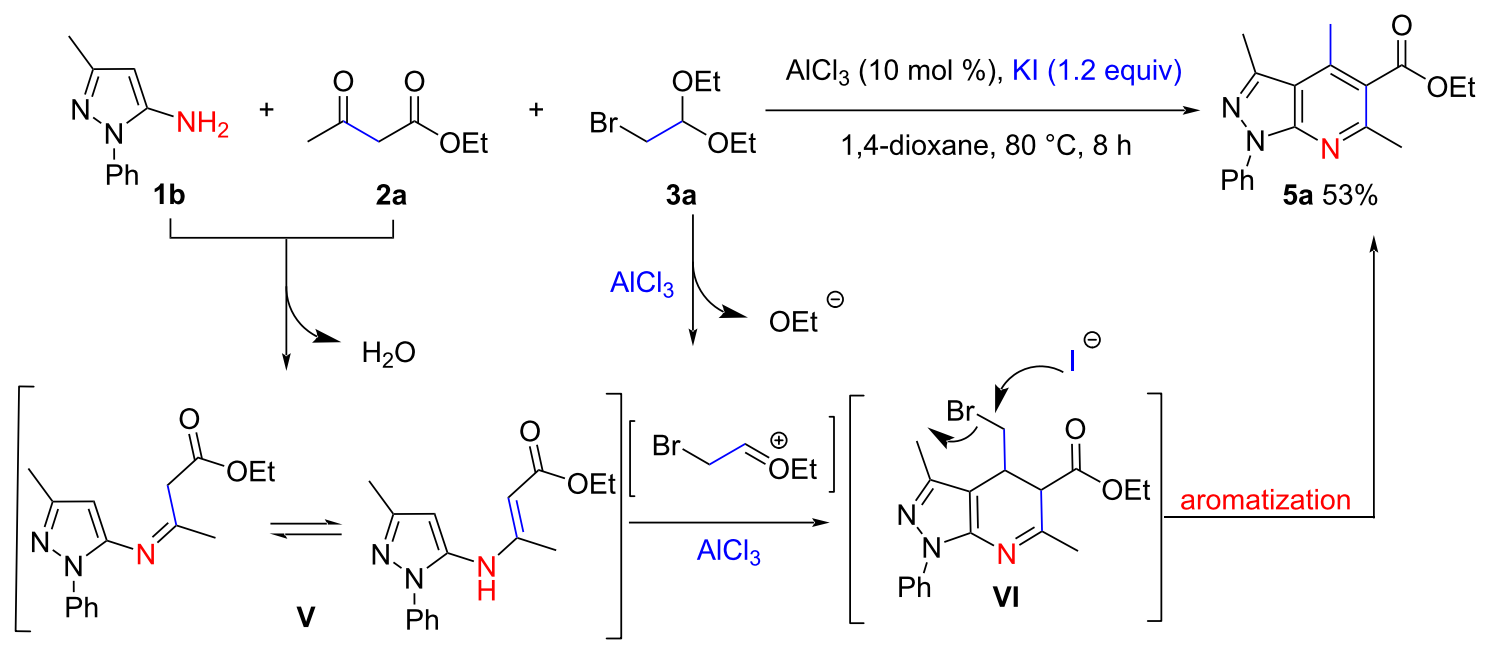

Scheme 6: Synthesis of polysubstituted pyrazolo[3,4-b]pyridine derivatives.

imine intermediate $\mathbf{V}$ may be involved in the reaction mechanism, and the enamine form of $\mathbf{V}$ contained two nucleophilic sites to react with a molecule of $\mathbf{3 a}$, which generated the intermediate VI. Finally, VI underwent an aromatization to produce 5a. KI may play a key role in the last step, and we suspected that it can promote the removal of bromide. Although 5a can theoretically be synthesized through a three-component reaction of $\mathbf{1 b}, \mathbf{2 a}$, and an appropriate aldehyde, for example, acetaldehyde [50,51] owing to the insufficient reactivity of aliphatic aldehydes, the reaction in Scheme 6 should be a wise choice for the synthesis of products similar in type to $\mathbf{5 a}$. This point deserves further investigation.

\section{Conclusion}

In summary, an efficient and practical one-pot multicomponent reaction of (hetero)arylamines with $\alpha$-bromoacetaldehyde acetal (2a) and 1,3-dicarbonyl compounds was developed by using $\mathrm{AlCl}_{3}$ as a catalyst. The developed chemistry is also successful for the synthesis of functionalized pyrazolo[3,4- $b]$ pyridine derivatives. This study offered a complementary method to construct pyrrole scaffolds through $[1+2+2]$ annulation, and thus enriching the product diversity of the pyrrole derivatives.

\section{Supporting Information}

\section{Supporting Information File 1}

Experimental procedures and copies of NMR spectra. [https://www.beilstein-journals.org/bjoc/content/ supplementary/1860-5397-16-241-S1.pdf]

\section{Funding}

The authors thank the Program for Leading Talents of Hubei Academy of Agricultural Sciences (L2018031) and the Natural Science Foundation of Hubei Province (2020CFB717), and the authors also thank the partial support from the Projects in the Youth Science Foundation of Hubei Academy of Agricultural Sciences (2021NKYJJ17) and Hubei Key Laboratory of Crop Diseases, Insect Pests and Weeds Control (2020ZTSJJ5), the Natural Science Foundation of Hubei Province (2019CFB219), and the National Natural Science Foundation of China (2171101076 and 21872060).

\section{ORCID ${ }^{\circledR}$ iDs}

Wenbo Huang - https://orcid.org/0000-0003-1507-6123

\section{Preprint}

A non-peer-reviewed version of this article has been previously published as a preprint: https://doi.org/10.3762/bxiv.2020.94.v1

\section{References}

1. O'Hagan, D. Nat. Prod. Rep. 2000, 17, 435-446. doi:10.1039/a707613d

2. Walsh, C. T.; Garneau-Tsodikova, S.; Howard-Jones, A. R. Nat. Prod. Rep. 2006, 23, 517-531. doi:10.1039/b605245m

3. Trost, B. M.; Dong, G. Org. Lett. 2007, 9, 2357-2359. doi:10.1021/ol070742y

4. Lindel, T.; Hochgürtel, M.; Assmann, M.; Köck, M. J. Nat. Prod. 2000, 63, 1566-1569. doi:10.1021/np000160o

5. Khajuria, R.; Dham, S.; Kapoor, K. K. RSC Adv. 2016, 6, 37039-37066. doi:10.1039/c6ra03411j

6. Osman, N. A.; Ligresti, A.; Klein, C. D.; Allarà, M.; Rabbito, A.; Di Marzo, V.; Abouzid, K. A.; Abadi, A. H. Eur. J. Med. Chem. 2016, 122, 619-634. doi:10.1016/j.ejmech.2016.07.012 
7. Hantzsch, A. Ber. Dtsch. Chem. Ges. 1890, 23, 1474-1476. doi:10.1002/cber.189002301243

8. Leonardi, M.; Estévez, V.; Villacampa, M.; Menéndez, J. C. Synthesis 2019, 51, 816-828. doi:10.1055/s-0037-1610320

9. Knorr, L. Ber. Dtsch. Chem. Ges. 1884, 17, 1635-1642. doi:10.1002/cber.18840170220

10. Paal, C. Ber. Dtsch. Chem. Ges. 1885, 18, 367-371. doi:10.1002/cber.18850180175

11. Balakrishna, A.; Aguiar, A.; Sobral, P. J. M.; Wani, M. Y.; Almeida e Silva, J.; Sobral, A. J. F. N. Catal. Rev.: Sci. Eng. 2019, 61, 84-110. doi:10.1080/01614940.2018.1529932

12. Bunrit, A.; Sawadjoon, S.; Tšupova, S.; Sjöberg, P. J. R.; Samec, J. S. M. J. Org. Chem. 2016, 81, 1450-1460. doi:10.1021/acs.joc.5b02581

13. Billedeau, R. J.; Klein, K. R.; Kaplan, D.; Lou, Y. Org. Lett. 2013, 15, 1421-1423. doi:10.1021/ol400062w

14. Andreou, D.; Kallitsakis, M. G.; Loukopoulos, E.; Gabriel, C.; Kostakis, G. E.; Lykakis, I. N. J. Org. Chem. 2018, 83, 2104-2113. doi:10.1021/acs.joc.7b03051

15. Firoozi, N.; Torres, G. M.; Arndtsen, B. A. J. Org. Chem. 2016, 81, 11145-11152. doi:10.1021/acs.joc.6b02102

16. Zheng, Y.; Wang, Y.; Zhou, Z. Chem. Commun. 2015, 51, 16652-16655. doi:10.1039/c5cc05624a

17. Singh, K.; Kabadwal, L. M.; Bera, S.; Alanthadka, A.; Banerjee, D. J. Org. Chem. 2018, 83, 15406-15414. doi:10.1021/acs.joc.8b02666

18. Herath, A.; Cosford, N. D. P. Org. Lett. 2010, 12, 5182-5185. doi:10.1021/ol102216x

19. Xu, J.; Green, A. P.; Turner, N. J. Angew. Chem., Int. Ed. 2018, 57, 16760-16763. doi:10.1002/anie.201810555

20. Chelucci, G. Coord. Chem. Rev. 2017, 331, 37-53. doi:10.1016/j.ccr.2016.09.014

21. Estévez, V.; Villacampa, M.; Menéndez, J. C. Chem. Soc. Rev. 2014 43, 4633-4657. doi:10.1039/c3cs60015g

22. Gulevich, A. V.; Dudnik, A. S.; Chernyak, N.; Gevorgyan, V. Chem. Rev. 2013, 113, 3084-3213. doi:10.1021/cr300333u

23. Estévez, V.; Villacampa, M.; Menéndez, J. C. Chem. Soc. Rev. 2010, 39, 4402-4421. doi:10.1039/b917644f

24. Ahmad, S.; Alam, O.; Naim, M. J.; Shaquiquzzaman, M.; Alam, M. M.; Iqbal, M. Eur. J. Med. Chem. 2018, 157, 527-561. doi:10.1016/j.ejmech.2018.08.002

25. Winters, M. P.; Sui, Z.; Wall, M.; Wang, Y.; Gunnet, J.; Leonard, J.; Hua, H.; Yan, W.; Suckow, A.; Bell, A.; Clapper, W.; Jenkinson, C.; Haug, P.; Koudriakova, T.; Huebert, N.; Murray, W. V. Bioorg. Med. Chem. Lett. 2018, 28, 841-846. doi:10.1016/j.bmcl.2018.02.013

26. Singh, A.; Mir, N. A.; Choudhary, S.; Singh, D.; Sharma, P.; Kant, R.; Kumar, I. RSC Adv. 2018, 8, 15448-15458. doi:10.1039/c8ra01637b

27. Thompson, B. B.; Montgomery, J. Org. Lett. 2011, 13, 3289-3291. doi:10.1021/ol201133n

28. Biletzki, T.; Imhof, W. Synthesis 2011, 3979-3990. doi:10.1055/s-0031-1289584

29. Tao, L.; Wang, Z.-J.; Yan, T.-H.; Liu, Y.-M.; He, H.-Y.; Cao, Y. ACS Catal. 2017, 7, 959-964. doi:10.1021/acscatal.6b02953

30. Lu, Y.; Fu, X.; Chen, H.; Du, X.; Jia, X.; Liu, Y. Adv. Synth. Catal. 2009, 351, 129-134. doi:10.1002/adsc.200800490

31. Thies, N.; Gerlach, M.; Haak, E. Eur. J. Org. Chem. 2013, 7354-7365. doi:10.1002/ejoc.201300803

32. Zhang, Z.; Zhang, W.; Li, J.; Liu, Q.; Liu, T.; Zhang, G. J. Org. Chem. 2014, 79, 11226-11233. doi:10.1021/j05018487
33. Kong, H.-H.; Pan, H.-L.; Ding, M.-W. J. Org. Chem. 2018, 83, 12921-12930. doi:10.1021/acs.joc.8b01984

34. Tracey, M. R.; Hsung, R. P.; Lambeth, R. H. Synthesis 2004, 918-922. doi:10.1055/s-2004-815976

35. Delayen, A.; Goossens, L.; Goossens, R.; Henichart, J.-P. Heterocycles 2005, 65, 1673-1678. doi:10.3987/com-05-10386

36. Lu, S.; Qi, L.; Li, Z. Asian J. Org. Chem. 2017, 6, 313-321. doi:10.1002/ajoc.201600608

37. Wang, M.; Liu, C.; Gu, Y. Tetrahedron 2016, 72, 6854-6865. doi:10.1016/j.tet.2016.09.014

38. Zhang, M.; Neumann, H.; Beller, M. Angew. Chem., Int. Ed. 2013, 52 , 597-601. doi:10.1002/anie.201206082

39. Zhang, M.; Fang, X.; Neumann, H.; Beller, M. J. Am. Chem. Soc. 2013, 135, 11384-11388. doi:10.1021/ja406666r

40. Chandrasekhar, S.; Patro, V.; Chavan, L. N.; Chegondi, R.; Grée, R. Tetrahedron Lett. 2014, 55, 5932-5935. doi:10.1016/j.tetlet.2014.08.105

41. Dang, T. T.; Seayad, A. M. Chem. - Asian J. 2017, 12, 2383-2387. doi:10.1002/asia.201701045

42. Zeng, J.-C.; Xu, H.; Huang, R.-L.; Yu, F.; Zhang, Z. Tetrahedron Lett. 2018, 59, 1576-1580. doi:10.1016/j.tetlet.2018.03.025

43. Shishido, Y.; Ohmi, M.; Ando, K. Azaspiro derivatives as trpm8 antagonists. WO Patent WO2015136947A1, Sept 17, 2015.

44. Sun, R.; Liu, Y.; Zhang, Y.; Xiong, L.; Wang, Q. J. Agric. Food Chem. 2011, 59, 2471-2477. doi:10.1021/jf104578j

45. Hirth-Dietrich, C.; Sandner, P.; Stasch, J.-P.; Hahn, M.; Follmann, M. The use of SGC stimulators, sGC activators, alone and combinations with PDE5 inhibitors for the treatment of systemic sclerosis (SSc). Eur. Patent EP2594270A2, May 22, 2013.

46. Boyer, T.; Dodic, N.; Evans, B.; Kirk, B. E. 2,6-disubstituted pyridines and 2,4-disubstituted pyrimidines as soluble guanylate cyclase activators. WO Patent WO2009068652A1, June 4, 2009.

47. Ushio, H.; Hamada, M.; Watanabe, M.; Numata, A.; Fujie, N.; Takashima, T.; Furukawa, H.; Ando, J. Amide derivative and use thereof. WO Patent WO2012050159A1, April 19, 2012.

48. Huang, W.; Liu, C.; Gu, Y. Adv. Synth. Catal. 2017, 359, 1811-1818. doi:10.1002/adsc.201700074

49. Huang, W.; Chen, S.; Chen, Z.; Yue, M.; Li, M.; Gu, Y. J. Org. Chem. 2019, 84, 5655-5666. doi:10.1021/acs.joc.9b00596

50. Tu, S.; Wang, Q.; Zhang, Y.; Xu, J.; Zhang, J.; Zhu, X.; Shi, F. J. Heterocycl. Chem. 2007, 44, 811-814. doi:10.1002/jhet.5570440409

51. Gunasekaran, P.; Indumathi, S.; Perumal, S. RSC Adv. 2013, 3, 8318-8325. doi:10.1039/c3ra00136a 


\section{License and Terms}

This is an Open Access article under the terms of the Creative Commons Attribution License (https://creativecommons.org/licenses/by/4.0). Please note that the reuse, redistribution and reproduction in particular requires that the author(s) and source are credited and that individual graphics may be subject to special legal provisions.

The license is subject to the Beilstein Journal of Organic Chemistry terms and conditions:

(https://www.beilstein-journals.org/bjoc/terms)

The definitive version of this article is the electronic one which can be found at:

https://doi.org/10.3762/bjoc.16.241 